\title{
Assessment of Wind Turbine Generators on Reliability of Distribution Network
}

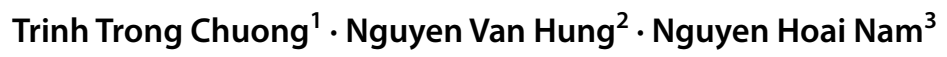

Received: 19 April 2018 / Revised: 25 March 2019 / Accepted: 12 June 2019 / Published online: 10 August 2019

(c) The Author(s) 2019

\begin{abstract}
Wind turbine generators (WTG) is predicted to play a prominent role in the electric power systems of the future. Connection of wind turbine generators to the distribution network increases power sources and therefore increases reliability of distribution network. Assessment of reliability of distribution network connected to wind turbine generators based on two state model yields big errors due to dependence of wind source capacity on wind speed which is a variable value. For more accurate assessment results, the article proposes to utilize multi-stage model of wind source reliability and switch section partitioning based on reliability on distribution network.
\end{abstract}

Keywords Wind turbine generators $\cdot$ Distribution network $\cdot$ Reliability $\cdot$ Multi stage mode

\section{Introduction}

The distribution networks (DNs) are responsible for supplying electricity directly to the consumers. Therefore, they are responsible for ensuring the quality of electricity service. Changes in grid configuration, status parameters and equipment status in the DNs directly affect the consumers through changes in power quality and power supply reliability [1]. In terms of power quality, DNs is mainly determined by voltage quality indicator. The most effective voltage regulating components such as transformers, compensators are located in the DNs. In different modes of the load, the DN could modify the configuration to ensure the determined voltage quality. In relation to the power supply reliability, DN plays a crucial role because power outage in $\mathrm{DN}$ could

Trinh Trong Chuong

chuonghtd@haui.edu.vn

Nguyen Van Hung

vanhung312@gmail.com

Nguyen Hoai Nam

hoainam.ies@gmail.com

1 HaUI Institute of Technology (HIT), Hanoi University of Industry, Hanoi, Vietnam

2 Department of Electrical Engineering, Hanoi University of Industry, Hanoi, Vietnam

3 Institute of Energy Science, Vietnam Academy of Science and Technology, Hanoi, Vietnam directly affect the power shortage on the load. In order to improve the reliability in the DN, several measures could be implemented such as installation of reclosers, isolators, grid reconfiguration, etc.

As a sequence, indicators such as the system average interruption frequency index (SAIFI), customer average interruption frequency index (CAIFI), system average interruption duration index (SAIDI), customer average interruption duration index (CAIDI) are widely used to evaluate the power reliability. Determining the relationship between these indicators and the change in power supply is the first step in introducing the solutions to enhance the power reliability of DNs.

One of the highly accurate methods for power reliability assessment is section partitioning. This method employs partinioning switch to partition the grid into secctions with different power reliabilities. It is assumed that failures of the fuses are neglectable, the durations of electricity service interupted to consumers in the same section are similar. Then, configuration by sections shall be basis for analyzing and calculating the power reliability to consumers. In one DN, it is possible to partition it into several load sections. These load sections could be patitioned by interconnected lines by non-automatic breakers devices such as cut-out fuses, disconnecting switch, load switch which are characterized by the same failure's causes and frequency [2]. The accuracy of calculating the power reliability depends on the reliability model of the elements in the DN. Normally the elements are modeled under 
two states of success and failure associated with two parameters of failure probability and resilience probability. With this model, higher errors may be expected as when modeling with multi-state generators such as Wind Turbine Generator (WTG). Recently, wind power integration to the DN has been increased to improve the power supply capability and reduce the probability of power shortage due to lack of power supply.

However, WTG is characterized by unmanageable output power which is entirely dependent on the wind speed as random variable. Thus, this article proposes to utilize multi-state model of wind source reliability and switch section partitioning based on reliability on distribution network to achieve more accurate results of calculating the yearly duration of power shortage due to failures.

\section{Reliability Model}

\subsection{Reliability Model of Multi-state WTG}

\subsubsection{Wind Velocity Model}

Wind speed varies by locations and time. A common expression of wind velocity randomness is the probability density function model Weibull [3].

$f(v)=\frac{k}{c}\left(\frac{v}{c}\right)^{k-1} \exp \left[-\left(\frac{v}{c}\right)^{k}\right]$

In which:

$\nu$ is wind velocity $(\mathrm{m} / \mathrm{s}) ; \mathrm{k}$ is the character index varies with the wind of each region (Fig. 1); $\mathrm{c}$ is the rate index calculated based on the average annual wind speed, calculated over several years, shown in Fig. 2.

Probability distribution function:

$F(v)=P(V \leq v)=1-\exp \left[-\left(\frac{v}{c}\right)^{k}\right]$

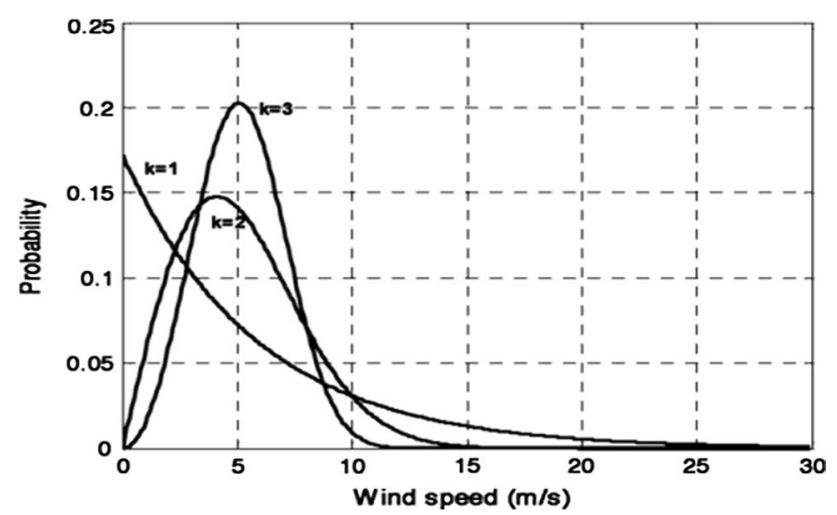

Fig. 1 Probability distribution function with different $\mathrm{k}$ values

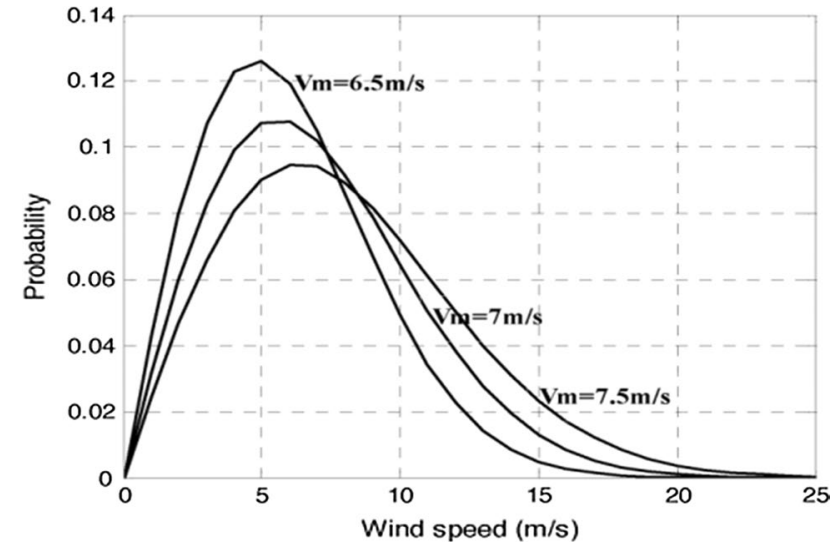

Fig. 2 Probability distribution function with different $\mathrm{c}$ values

In this paper, the distribution of wind speed probabilities is described based on the annual average value $\mu$ and standard deviation $\sigma$ [3]. With deviation range $10 \sigma$, the distribution will include very low probability values. The distribution is divided into $\mathrm{N}_{\mathrm{b}}$ steps at scale of $10 \sigma / \mathrm{N}_{\mathrm{b}}$. Step center value $\mathrm{SW}_{\mathrm{bi}}\left(\mathrm{i}=1, \ldots, \mathrm{N}_{\mathrm{b}}\right)$ is defined in Eq. (3) corresponding to the probability of each step $\mathrm{P}_{\mathrm{bi}}\left(\mathrm{i}=1, \ldots, \mathrm{N}_{\mathrm{b}}\right)$ is defined in the Eq. (4).

$\left\{\begin{array}{l}S W_{b i}=\mu+\left(\frac{10 \sigma}{N_{b}}\right)\left(i-0.5 N_{b}\right) \quad \text { with } N_{b} \text { as even number } \\ S W_{b i}=\mu+\left(\frac{10 \sigma}{N_{b}}\right)\left[i-0.5\left(N_{b}+1\right)\right] \text { with } N_{b} \text { as odd number }\end{array}\right.$

$P_{b i}=\frac{N_{b i}}{8760 \cdot N_{y}}$

where $\mathrm{N}_{\mathrm{bi}}$ is the number of wind speed data simulation; $\mathrm{N}_{\mathrm{y}}$ is the number of years of simulation (Fig. 3).

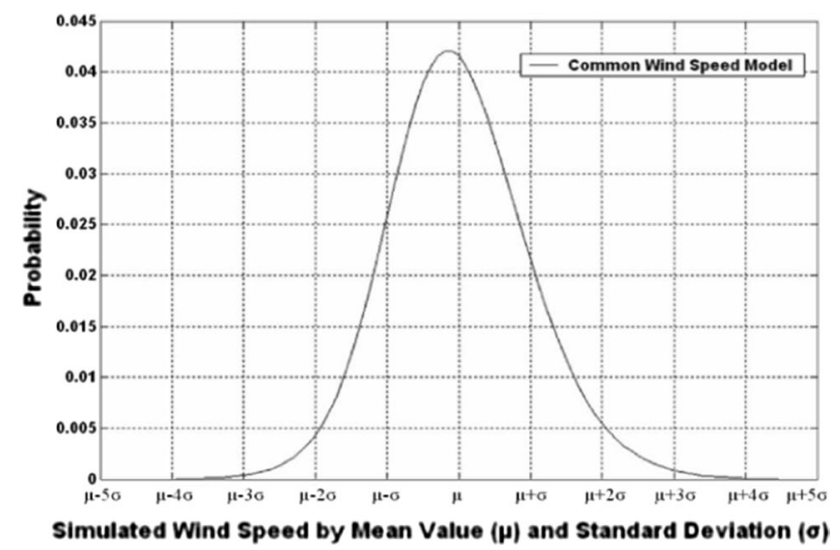

Fig. 3 Simulation of wind speed by mean value in $\mu$ and standard deviation $\sigma[3]$ 


\subsubsection{Generating Capacity Model of WTG}

Generating capacity of WTG directly depends on wind speed. Typical speed thresholds for each WTG:

$\mathrm{V}_{\mathrm{ci}} \quad$ minimum operational wind speed;

$V_{r} \quad$ wind speed for starting the turbine reaching the rated power;

$\mathrm{V}_{\text {co }}$ maximum wind speed allows turbines to operate (for reasons of safety for turbines when the wind is over speed) (Fig. 4).

For each wind speed value is a generating output value:

$\begin{cases}P_{i}=0 & 0 \leq S \mathrm{~W}_{b i} \leq V_{c i} \\ P_{i}=P_{r}\left(A+B \cdot S \mathrm{~W}_{b i}+C \cdot S \mathrm{~W}_{b i}^{2}\right) & V_{c i} \leq S \mathrm{~W}_{b i} \leq V_{r} \\ P_{i}=P_{r} & V_{r} \leq S \mathrm{~W}_{b i} \leq V_{c o} \\ P_{i}=0 & V_{c o} \leq S \mathrm{~W}_{b i}\end{cases}$

Values of A, B, C are calculated in the following formulas [5]:

$$
\left\{\begin{array}{l}
A=\frac{1}{\left(V_{c i}-V_{r}\right)^{2}}\left[V_{c i}\left(V_{c i}+V_{r}\right)-4\left(V_{c i} V_{r}\right)\left(\frac{V_{c i}+V_{r}}{2 V_{r}}\right)^{3}\right] \\
B=\frac{1}{\left(V_{c i}-V_{r}\right)^{2}}\left[4\left(V_{c i}+V_{r}\right)\left(\frac{V_{c i}+V_{r}}{2 V_{r}}\right)^{3}-\left(3 V_{c i}+V_{r}\right)\right] \\
C=\frac{1}{\left(V_{c i}-V_{r}\right)^{2}}\left[2-4\left(\frac{V_{c i}+V_{r}}{2 V_{r}}\right)^{3}\right]
\end{array}\right.
$$

\subsubsection{Multi-state Model of WTG}

For WTG with the generating depends on the change in wind speed, the two-state model is unable to describe all generating states. Therefore, it is required to use a multistate model in order to accurately depict the actual state of the WTG. Each state is characterized by the state power $P_{i}$ and the state probability $\mathrm{P}_{\mathrm{Bi}}$ shown in Fig. 5.

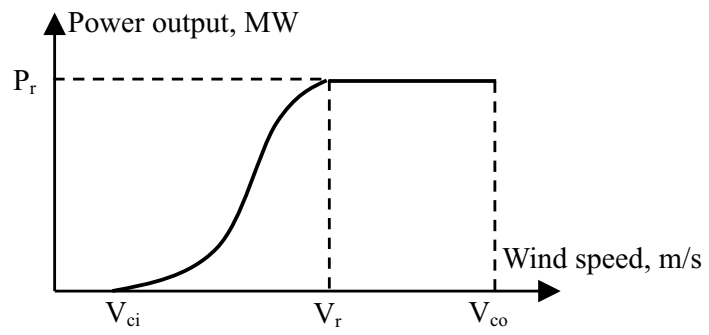

Fig. 4 Characteristics of WTG output power at wind speed [4]

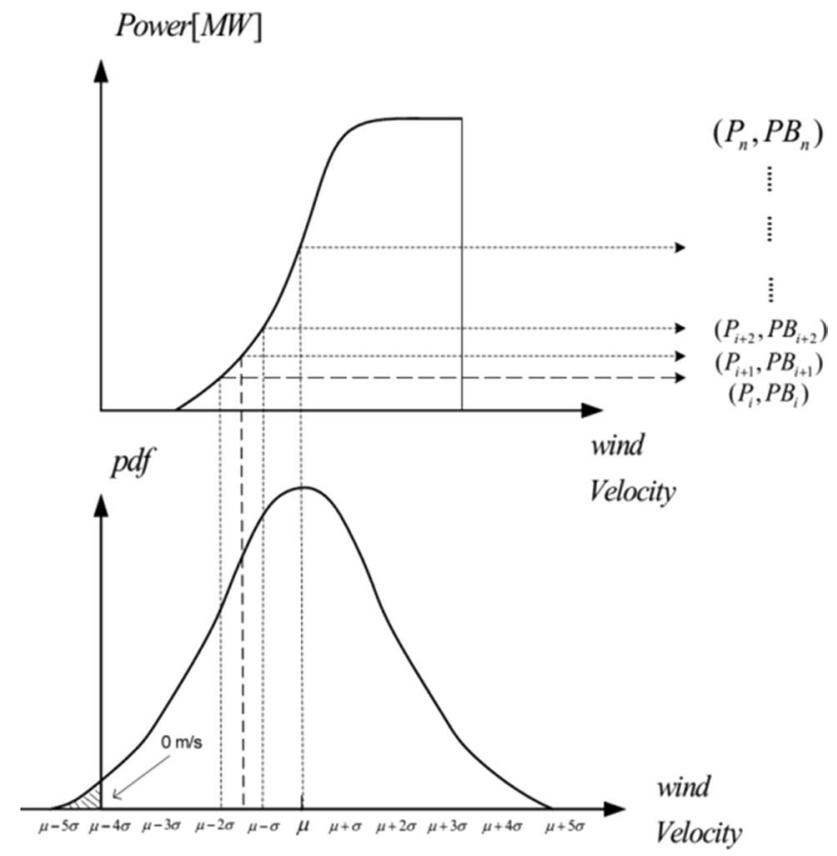

Fig. 5 Status probability of generating capacity of WTG

The multiple state model presents many advantages that accurately describe the working status of the WTG changes according to wind speed. However, the model encountered many difficulties when calculating the probability of special states when number of states is high. Therefore, simplified multi-state model was proposed in [6] as in Fig. 6.

$$
\left\{\begin{array}{l}
P B_{k}=\left(\frac{P_{k+1}-P_{i}}{\Delta P}\right) \cdot P B_{i} \\
P B_{k+1}=\left(\frac{P_{i}-P_{k}}{\Delta P}\right) \cdot P B_{i}
\end{array}\right.
$$

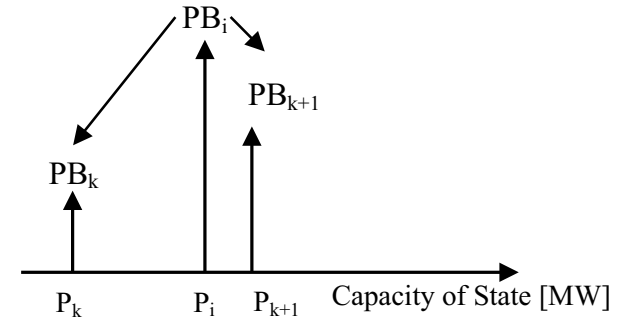

Fig. 6 Simplified multi-state model 


\subsection{Computation of Reliability in Distribution Network}

\subsubsection{Distribution Network Section Partitioning}

During the reliability calculations, complex grids are often partitioned into sections with the same reliability parameters. With the DN having large number of nodes, partitioning DN into sections is necessary so as to simplify reliability computation. Section partitioning by reliability is subject to location of the switch. If the failure of the fuse is assumed to be neglectable, the supply of electricity to consumers in the one section is the same. In fact, section partitioning based on automatic switches devices also help improving reliability. In case of failure, sections isolated from the main grid could be offgrid. Distributed generators feeding to these offgrid sections may become main supplier for those sections' loads.

Determination of isolating location to ensure continuous power supply to the load depends on the correlation between the distributed generator capacity and the loads. For the proactive generators such as diesel, small hydropower, it is possible to determine the power source. Whereas, determination of isolating location faces many difficulties with distributed generator which generating capacity depends randomly on the wind speed parameter.

The IEEE RBTS 25 node grid model on Fig. 7 [7] is partitioned into five sections with different reliability. In particular, in order to improve reliability of Sects. 2, 3, 4, 5, WTG was integrated. These sections can be isolated from the main grid to operate independently in case of failure through the island conditioning unit such as circuit breaker. In the absence of wind power, the cause of the power failure in each Area ith $\left(\mathrm{KV}_{\mathrm{i}}\right)$ can be a fault on the distribution station (DS) that located on the line connected to $\mathrm{KV}_{\mathrm{i}}$ from the main power supply or on $\mathrm{KV}_{\mathrm{i}}$ itself. For example, for $\mathrm{KV} 3$ on set $\mathrm{G} 4=\{\mathrm{KV} 1$, $\mathrm{KV} 3, \mathrm{KV} 4, \mathrm{DS}$ \}. For every failure of each component of the set $\mathrm{G}$, the power failure duration on KV4 is the duration of repair of the defective part [7].

Then, duration of the power outage is calculated as follows:

$T_{k}^{N D}=\left(\sum_{j \in G} \sum_{i=1}^{m} \lambda_{i} \cdot r_{i}\right)$

In which:

$\mathrm{T}_{\mathrm{k}}^{\mathrm{ND}}$ is the duration of off-grid for section $\mathrm{k} ; \lambda_{\mathrm{i}}$ is fail intensity of element $i$ in element $j ; r_{i}$ is duration of repairing of element $\mathrm{i}$; and $\mathrm{m}$ is the number of elements in section $\mathrm{i}$.

If every section is consider as smaller system within DNs, each section has SAIDI $_{k}$ and the whole system has SAIDI ${ }_{\mathrm{s}}$. The two indexes are associated through the formula (9):

$\operatorname{SAIDI}_{s}=\sum_{k} \operatorname{SAIDI}_{k} \cdot \frac{C_{k}}{C_{s}}$

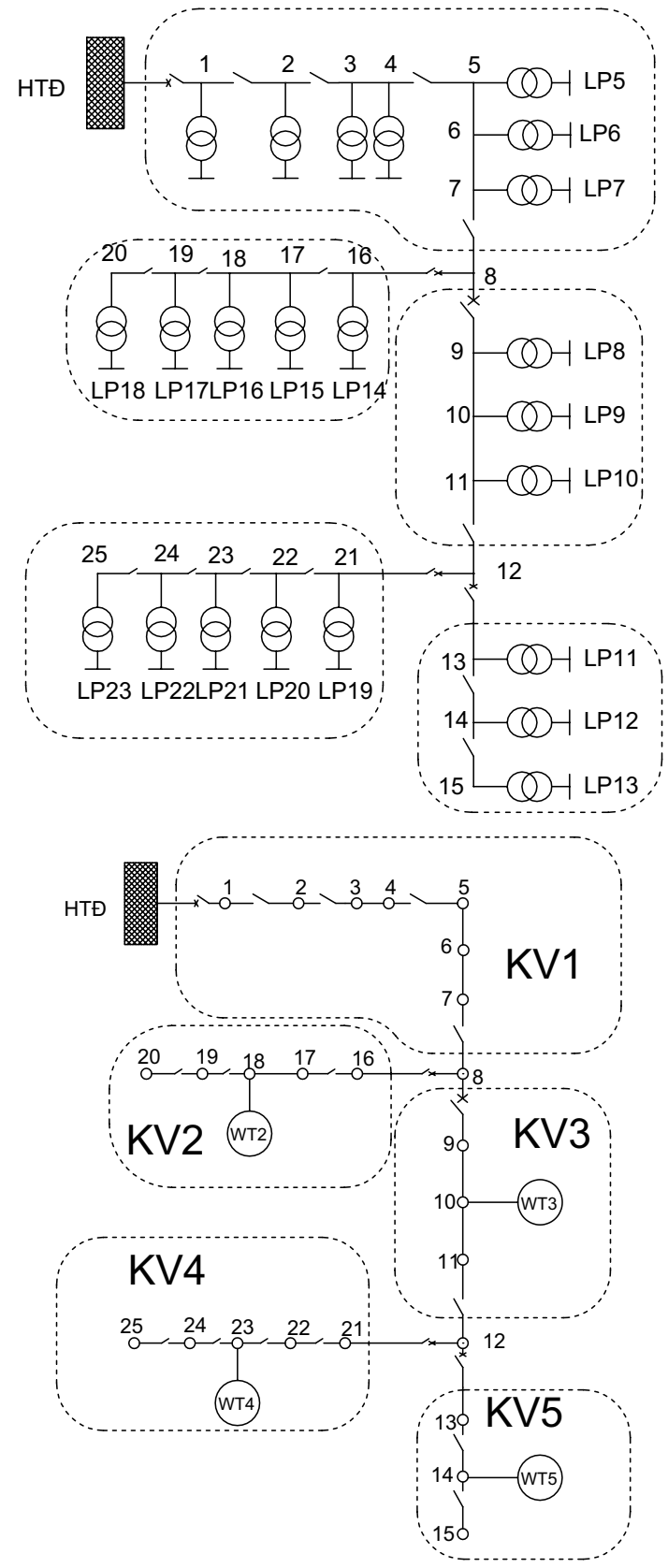

Fig. 7 Section partitioning of grid by reliability

In which:

$\mathrm{C}_{\mathrm{k}}$ is the number of load in section $\mathrm{k} ; \mathrm{C}_{\mathrm{s}}$ : total number of loads in the whole DN.

In fact, duration of power shortage is different with formula (13), because sections have distributed generator and operating off-grid. Thus, it is necessary to include the probability function of off-grid mode as follows:

$P_{k}^{T L}=\frac{\sum_{j \in G \cap j \neq k} T_{j}^{N D}}{8760}$ 


\subsection{Calculating Power Reliability of Distribution Network}

In section a, the probability of operation in off-grid mode has been discussed. However, the success of grid isolation is subject to co-relation between capacity of distributed generators and load capacity at the time of isolation. To calculate the reliability indices, it is necessary to calculate the probability of power shortage, when power shortages occur:

$P_{K}^{T H}=P\left(S_{\mathrm{W} T G}<S_{L}\right)=\sum_{i=1}^{n} P b_{i} \cdot \frac{\tau_{i}}{8760}$

In which:

$\mathrm{S}_{\mathrm{WTG}}$, capacity of wind power integrated to the section in off-grid mode; $\mathrm{S}_{\mathrm{L}}$ : load capacity at the time of grid isolation; $\tau_{\mathrm{i}}$, is the time of $\mathrm{S}_{\mathrm{WTG}}<\mathrm{S}_{\mathrm{L}}$, is determined based on extended load curve of the section and capacity $\mathrm{P}_{\mathrm{i}}$ at the state $\mathrm{i}$.

From the formula (10) and (11), probability of power shortage when isolating from the grid for the section in consideration:

$P_{K}^{T L-\mathrm{OFF}}=P_{K}^{T L} \cdot P_{K}^{T H}$

Sectional reliability is determined:

$$
\begin{aligned}
S A I D I_{k}^{\mathrm{WTG}} & =8760 \cdot P_{K}^{T L-\mathrm{OFF}}+\sum_{\substack{i=1 \\
j=k}}^{m} \lambda_{i} \cdot r_{i} \\
& =\left(\sum_{j \in G \cap j \neq k} \sum_{i=1}^{m} \lambda_{i} \cdot r_{i}\right) \cdot \sum_{i=1}^{n} P b_{i} \cdot \frac{\tau_{i}}{8760}+\sum_{\substack{i=1 \\
j=k}}^{m} \lambda_{i} \cdot r_{i}
\end{aligned}
$$

Once sectional reliability is determined, system reliability can be identified by formula (9).

\section{Case Study}

\subsection{Network Configuration}

See Table 1 here.

\subsection{Wind Power Source}

One WTG with parameter given in Table 2.

\subsection{Absence of WTG}

Based on set in Tables 1, 2, 3, 4, 5, SAIDI index was determined for sections and for system in the absence of WTG. Results are shown in Table 6 (Fig. 8).

Table 2 WTG parameters

\begin{tabular}{lllll}
\hline $\mathrm{V}_{\text {cut-in }}$ & $\mathrm{V}_{\mathrm{r}}$ & $\mathrm{V}_{\text {cut-out }}$ & $\mathrm{P}_{\mathrm{r}}, \mathrm{kW}$ & $\lambda$ (time/year) \\
\hline $4 \mathrm{~m} / \mathrm{s}$ & $14 \mathrm{~m} / \mathrm{s}$ & $25 \mathrm{~m} / \mathrm{s}$ & 1000 & 0.04 \\
\hline
\end{tabular}

$\mathrm{A}=0.12506 ; \mathrm{B}=-0.06877(\mathrm{~m} / \mathrm{s})^{-1} ; \mathrm{C}=0.00938(\mathrm{~m} / \mathrm{s})^{-2}$

Table 3 Statistics of wind speed in the year

\begin{tabular}{lllr}
\hline $\begin{array}{l}\text { Wind speed } \\
(\mathrm{m} / \mathrm{s})\end{array}$ & h/year & Wind speed $(\mathrm{m} / \mathrm{s})$ & $\mathrm{h} /$ year \\
\hline $0 \div 4$ & 1104 & $10 \div 12$ & 1232 \\
$4 \div 6$ & 1355 & $12 \div 14$ & 1124 \\
$6 \div 8$ & 1490 & $14 \div 25$ & 811 \\
$8 \div 10$ & 1572 & $25 \div 35$ & 72 \\
\hline
\end{tabular}

Table 4 Statistical data of WTG output generating capacity

\begin{tabular}{lll}
\hline $\begin{array}{l}\text { WTG } \\
\text { capacity, } \\
\text { kW }\end{array}$ & $\begin{array}{l}\text { State probability (Without } \\
\text { consideration to failures of } \\
\text { WTG) }\end{array}$ & $\begin{array}{l}\text { State probability (con- } \\
\text { sideration to failures of } \\
\text { WTG) }\end{array}$ \\
\hline 0 & 0.1342 & 0.1635 \\
15.71 & 0.1547 & 0.1485 \\
103.29 & 0.1700 & 0.1632 \\
265.91 & 0.1794 & 0.1722 \\
503.57 & 0.1406 & 0.1350 \\
816.27 & 0.1283 & 0.1232 \\
1000 & 0.0926 & 0.0889 \\
\hline
\end{tabular}

Table 1 Parameters of distribution network

\begin{tabular}{lllll}
\hline & Description & $\lambda$ (time/year) & $\begin{array}{l}\text { Duration of } \\
\text { repair (h) }\end{array}$ & $\begin{array}{l}\text { Average dura- } \\
\text { tion of fail (h/ } \\
\text { year) }\end{array}$ \\
\hline Main distribution station & - & $0.6 / 100$ & 24 & 0.144 \\
Circuit breaker & - & $0,36 / 100$ & 32 & 0.1152 \\
Transformer 22/0.4 kV & $400 \mathrm{kVA}$ & $1.5 / 100$ & 10 & 0.15 \\
Length of grid at each section & $3 \mathrm{~km}$ & $6.5 / 100(1 / \mathrm{km})$ & 5 & 0.325 \\
Number of customers at each node & 80 customers & - & - & - \\
\hline
\end{tabular}


Table 5 Set $\mathrm{G}$ of sections

\begin{tabular}{ll}
\hline Section & Set G \\
\hline 1 & $\{$ Substation PP, KV1\} \\
2 & $\{$ Substation PP, KV1, KV2\} \\
3 & $\{$ Substation PP, KV1, KV3 \\
4 & $\{$ Substation PP, KV1, KV3, KV4\} \\
5 & $\{$ Substation PP, KV1, KV3, KV5 \\
\hline
\end{tabular}

Table 6 SAIDI in sections in the absence of WTG

\begin{tabular}{lll}
\hline Section & SAIDI $_{\mathrm{k}}$ (h/year) & Number of customer in the section \\
\hline 1 & 2.2842 & 560 \\
2 & 4.1244 & 400 \\
3 & 3.8244 & 240 \\
4 & 5.6646 & 400 \\
5 & 5.3646 & 240 \\
SAIDI $_{\mathrm{s}}$ & 4.0218 & 1980 \\
\hline
\end{tabular}
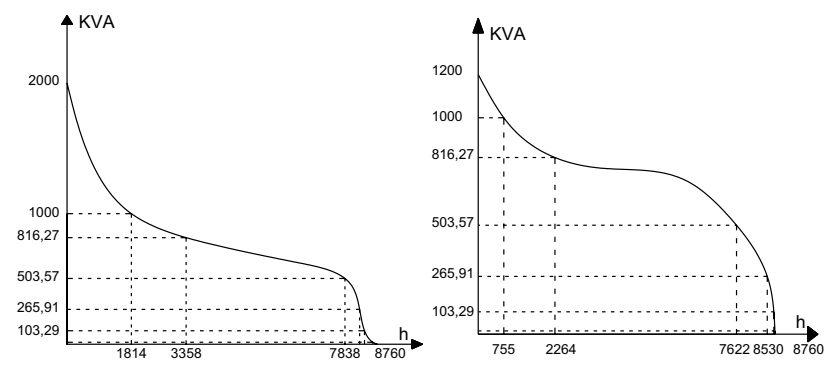

Fig. 8 Extended load curve of KV4 (on the left) and KV5 (on the right)

\subsection{Considering Integrating WTG}

Considering integrating WTG in Table 2 into DN. Calculating $\mathrm{SAIDI}_{4}$, off-grid probability:

$P_{4}^{T L}=\frac{\sum_{j \in G 4 \cap j \neq 4} T_{j}^{N D}}{8760}=4.36 \times 10^{-4}$
In off-grid mode, power shortage may occur when WTG is unable to meet the demand. Power shortage probability is detemined based on time of power shortage expressed in load curve in different states of wind power (Table 7 and Figs. 9, 10). The same process was applied for other sections, the results are shown in Table 8.

$\mathrm{SAIDI}_{4}^{\mathrm{WT}}=8760 \cdot P_{4}^{T L} \cdot P_{4}^{T H}+\sum_{\substack{i=1 \\ j=4}}^{m} \lambda_{i} \cdot r_{i}=4.9041 \mathrm{~h} /$ year

The calculation results in Table 8 and Fig. 11 indicate that:

- The average System Average Interruption Duration of DN with WTG integrated is substantially improved compared to the case of DN without WTG integrated, especially in sections directly connected to the WTG.

- The similar results are also found in the offgrid mode, when the WTG capacity increases, the probability of power loss and power loss time decreases. When capacity of wind power is significant enough compared to total load capacity in the DN, the power supply reliability has been significantly improved.

- Section partitioning contributes to improve accuracy of power reliability assessment. The power reliability model of multi-state WTG facilitate the consideration of randomness of wind power and load characteristics explicitly.

\section{Conclusion}

Determining the power reliability of DN integrating wind power is a complex problem. When considering this, it is necessary to take into account influencing factors, especially DN configurations, randomness of wind speed affecting WTG generating capacity and load characteristics. For wind power, the traditional reliability model is
Table 7 Probability of power shortage in off-grid mode KV4

\begin{tabular}{lllll}
\hline Section & $\begin{array}{l}\text { WTG generating } \\
\text { capacity }\end{array}$ & Power probability & $\begin{array}{l}\text { Time of } \\
\text { shorage/8760 h }\end{array}$ & Shorage probability \\
\hline 1 & 0 & 0.1635 & 8760 & 0.163500 \\
2 & 15.71 & 0.1485 & 8343 & 0.141431 \\
3 & 103.29 & 0.1632 & 8214 & 0.153028 \\
4 & 265.91 & 0.1722 & 7975 & 0.156769 \\
5 & 503.57 & 0.1350 & 7838 & 0.120791 \\
6 & 816.27 & 0.1232 & 3358 & 0.047227 \\
7 & 1000 & 0.0889 & 1814 & 0.018409 \\
Total & & & & 0.801155 \\
\hline
\end{tabular}




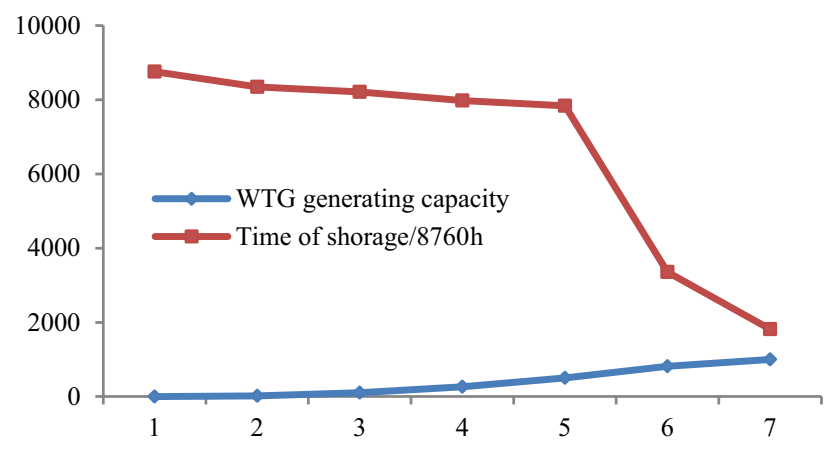

Fig. 9 The relationship between wind turbine capacity and capacity shortage

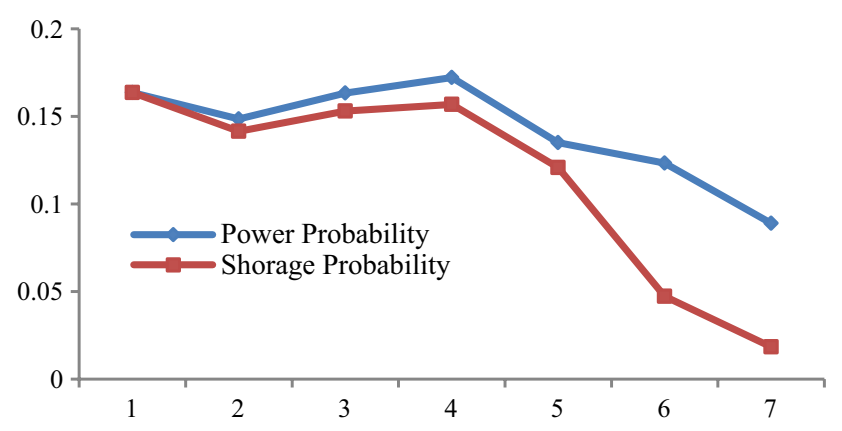

Fig. 10 The relationship between Power probability and shorage probability

Table 8 SAIDI index for each section and the system

\begin{tabular}{llll}
\hline Section & \multicolumn{2}{l}{ SAIDI $_{\mathrm{k}}$ (h/year) } & Difference, \% \\
\cline { 2 - 3 } & $\begin{array}{l}\text { With WTG } \\
\text { integrated }\end{array}$ & $\begin{array}{l}\text { Without WTG } \\
\text { integrated }\end{array}$ & \\
\hline 1 & 2.2842 & 2.2842 & 0 \\
2 & 4.1244 & 3.6702 & 11.01 \\
3 & 3.8244 & 3.3654 & 12.00 \\
4 & 5.6646 & 4.9041 & 13.43 \\
5 & 5.3646 & 4.5962 & 14.32 \\
System & 4.0218 & 3.5048 & 12.85 \\
\hline
\end{tabular}

no longer suitable because it is unable to stimulate states of WTG.

The multi-state model should be used for this purpose. This study has employed a multi-state model of wind power to calculate several reliability indexes considering the characteristics of the sectional load. In this paper, we have not considered in the case of DN integrated by multiple distributed power sources with different generating capacity characteristics. However, it is probable that the proposed method is capable to investigate such problems.

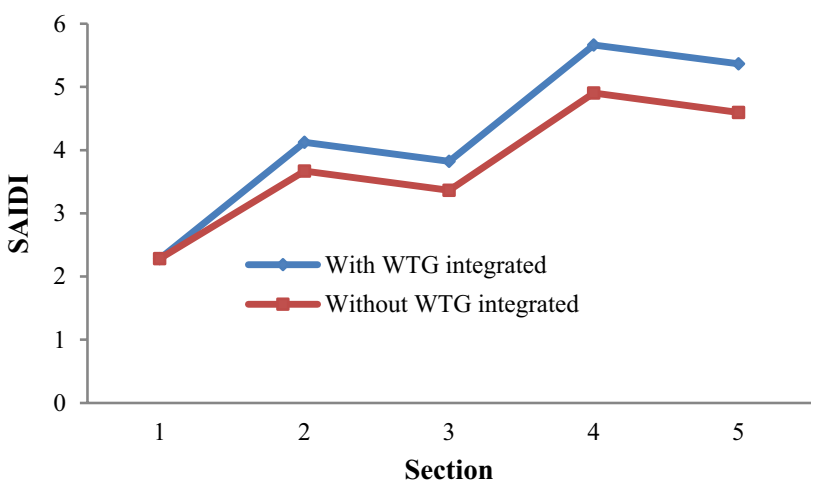

Fig. 11 SAIDI index for each section (with and without WTG integrated)

Acknowledgements This paper is developed as a subsidiary component of the study "Research on methodology and software to assess the power system reliability with consideration of renewable energy and other fuels for Vietnam power plants" Code: VAST.07.04/16-17. The authors specially thank the Vietnam Academy of Science and Technology-Institute of Energy Science for providing fund and creating favor in data collection during the implementation of the study.

Open Access This article is distributed under the terms of the Creative Commons Attribution 4.0 International License (http://creativeco mmons.org/licenses/by/4.0/), which permits unrestricted use, distribution, and reproduction in any medium, provided you give appropriate credit to the original author(s) and the source, provide a link to the Creative Commons license, and indicate if changes were made.

\section{References}

1. von Meier A (2006) Electric Power systems: a conceptual introduction. Wiley-IEEE Press, Hoboken

2. Duc Hanh N (2011) Invetigation on improvement of economic efficiency, voltage quality and reliability in the planning of medium voltage electrical network, Doctoral thesis; Hanoi (in Vietnamese)

3. Boyle G (2004) Renewable energy. Oxford University Press, Oxford

4. Wu L, Park J, Choi J, EI-Keib AA (2009) Probabilistic reliability evaluation of power systems including wind turbine generators considering wind speed correlation. J Electr Eng Technol. https ://doi.org/10.5370/JEET.2009.4.4.485

5. Cheng H, Hou Y, Wu F (2014) Probabilistic wind power generation model: derivation and applications. Int J Energy 5(2):17-26

6. Ding Y, Cheng L, Zhang Y, Xue Y (2014) Operational reliability evaluation of restructured power systems with wind power penetration utilizing reliability network equivalent and time-sequential simulation approaches. J Modern Power Syst Clean Energy 2(4):329-340

7. Atwa YM, El-Saadany EF (2009) Reliability evaluation for distribution system with renewable distributed generation during islanded mode of operation. IEEE Trans Power Syst 24:2

Publisher's Note Springer Nature remains neutral with regard to jurisdictional claims in published maps and institutional affiliations. 


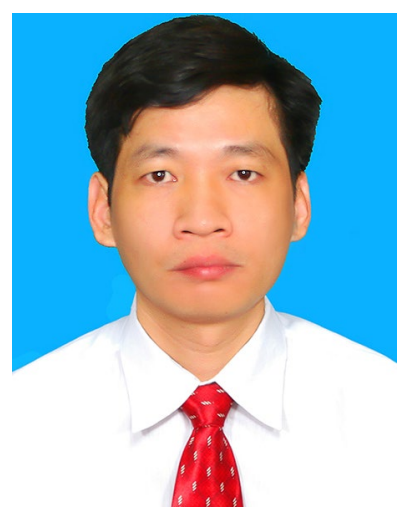

Trinh Trong Chuong currently working at $\mathrm{HaUI}$ Institute of Technology, Hanoi University of Industry. Chuong graduated from Hanoi University of Technology in 1999, major in Electrical System followed by a Master's degree and $\mathrm{Ph} . D$. in Electrical Engineering in 2003 and 2012 respectively. Currently, he is an Associate Professor at the Hanoi University of Industry, Vietnam. His current main research topic include: reconfiguration of the distribution network, voltage stabilization and power supply reliability.

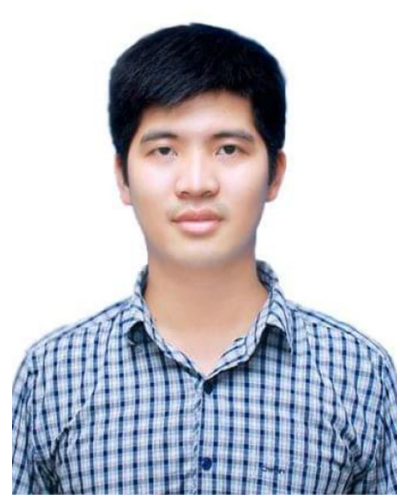

Nguyen Van Hung is currently working at the Department of Power System, Hanoi Industrial University. He graduated from Hanoi University of Technology in 2011, major in Electrical System. In 2014, Hung obtained Master degree of Electrical Engineering at the Hanoi University of Technology in 2014. His current main research are reliability in power system and distributed power generations.

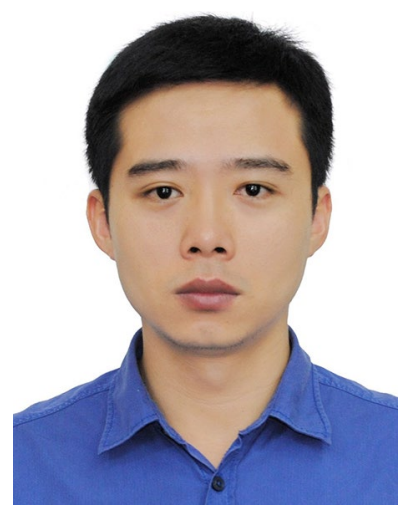

Nguyen Hoai Nam is director of Center for Energy System Research at VAST Insitute of Energy Science. Nam obtained his Ph.D in 2018. He has also the background in Sustainable Development, Environmental Management and Electrical Engineering in various graduate schools in Vietnam and Australia. Since 2009, Nam's major research topic is energy systems reliability and planning employing various integrated energy models. Nam has published more than 20 articles in peer-reviewed journals in energy systems and economics of renewable energy. 